\title{
Sizing of Stand-Alone Solar PV and Storage System With Anaerobic Digestion Biogas Power Plants
}

\author{
Chun Sing Lai, Student Member, IEEE, and Malcolm D. McCulloch, Member, IEEE
}

\begin{abstract}
This paper presents a deterministic approach for sizing a solar photovoltaic (PV) and energy storage system (ESS) with anaerobic digestion (AD) biogas power plant (BPP) to meet a proportional scaled-down demand of the national load in Kenya, Africa. The aim is to achieve a minimal levelized cost of energy (LCOE) for the system while minimizing the energy imbalance between generation and demand due to AD generator constraint and solar resource. This system also aims to maximize the sizing of PV as to follow the future trend of high penetration of PV. LCOE for the system and a levelized cost of delivery (LCOD) are calculated for the hybrid energy system with the presence of energy storage. Four years of solar data collected from Johannesburg, Africa, are used for system sizing purposes. An in-depth study of the optimization problem has been given and particle swarm optimization with the interior point method is chosen for solar panel sizing. The optimal sizing ratio for the generation sources $A D$ and $P V$ is 2.4:5. The results show that the hybrid system will be cost effective compared to the AD-only system when the discount rate drops below $8 \%$ with the current technology costs.
\end{abstract}

Index terms: Anaerobic digestion (AD), levelized cost of energy (LCOE), microgrid, optimal sizing, particle swarm optimization, photovoltaic (PV).

\section{INTRODUCTION}

ACCESS to modern energy services has important links

to economic development, poverty alleviation, and improved health. Despite these links, over 590 million people in sub-Saharan African remain without access to electricity [1]. The following two important aspects of the African context motivated this study.

1) Africa has an abundant solar resource. At present, it is harnessed only for small-scale applications (i.e., solar home systems).

2) Biogas power plant (BPP) powered by anaerobic digestion $(A D)$ can be used to facilitate the integration of intermittent renewable sources, such as solar and wind, by offsetting diurnal fluctuations in output.

The authors are with the Energy and Power Group, Department of Engineering Science, University of Oxford, Oxford, OX1 3PJ, U.K. (e-mail: chun.lai@eng.ox.ac.uk; malcolm.mcculloch@eng.ox.ac.uk).
The aim of this paper is to size the components of the hybrid stand-alone system to provide a minimal levelized cost of energy (LCOE). Energy balance is of fundamental importance for the successful operation of the energy system. The energy imbalance between generation and demand due to AD generator constraint and solar resource will be studied for the sizing purposes. The system is sized with a bias to provide a high penetration of photovoltaic (PV) energy. Several countries are aiming to maximize their solar energy portfolios. In USA, the Energy Secretary has announced that up to $\$ 87$ million will be made available to support the development of new solar energy technologies and the rapid deployment of available carbon-free solar energy systems [2]. In China by 2050, $2.7 \mathrm{TW}$ of solar power will be installed with a total annual output of 9.66 trillion $\mathrm{kWh}$, which accounts for $64 \%$ of China's total power generation [3]. In India, the Jawaharlal Nehru National Solar Mission has been initiated to promote the deployment of solar PV energy. It is expected that $20 \mathrm{GW}$ of power will be produced from solar PV by 2022 and there will be a significant increase in the number of off-grid projects, reaching $1 \mathrm{GW}$ by 2017 and $2 \mathrm{GW}$ by 2022 [4], [5]. The paper also provides insights of LCOE when considering storage, which the authors believe this has not been given a fair treatment previously.

In order to maximize the success of PV systems, a high reliability and a reasonable cost design must be achieved in the proposed PV topologies. Several standards given by the utility companies must be met in the PV module connection. Nowadays, the standards EN61000-3-2, IEEE1547, IEC61850, as well as the U.S. National Electrical Code 690, and the future international standard IEC61727 are being considered [6]-[8]. These standards deal with issues such as power quality, detection of islanding operation, grounding, etc. In the future, new standards need to be proposed to improve the economical evaluation of photovoltaic with storage integrated power systems.

Section II presents an extensive review on optimal sizing of stand-alone hybrid renewable energy systems. Section III provides an overview of the pyranometer data collected for the sizing problem. Section IV defines the research context and the optimization problem. Section V compares the optimization methods and Section VI introduces a framework for daily optimal sizing of solar system is presented. Section VII provides the components sizing of the system. The LCOE analysis is then presented in Section VIII, following with conclusion and future work in Section IX. 


\section{LITERATURE REVIEW}

Determining the optimal solution for a stand-alone hybrid renewable energy systems optimization problem is a complicated task because of the high number of variables and the nonlinearity in the performance of some of the system components [9]. The use of AD BPP has not been included in the study. A model aimed to minimize the cost of the PV system according to minimization of the PV array area and storage battery is presented in [10]. The method calculates the minimum number of storage days and the minimum PV array area. A comparison between the stand-alone and hybrid system sizing is presented in this paper. It is noted that the cost has not been evaluated for the system. The study uses average solar irradiance to determine the PV module characteristics, which does not take the daily fluctuation of solar irradiance and daily energy storage requirement into account.

A PV-diesel hybrid power system with battery backup for a village with the computer package HOMER is presented in [11]. HOMER [12] is an optimization software package that simulates different renewable energy sources system layouts and sized them on the basis of net present cost. It uses sensitive analysis to consider different generation capacities and battery storage capacity to determine the optimal size of the system. The issue with this program is the high computational requirement, due to the large number of cases needed to be computed. The study required a total of 448000 runs based on 28 sensitivities, where sensitivities are defined as the sizing control parameters, such as size of PV, diesel generator, etc. Also, the software is of "Black Box" code utilization, where knowledge of its internal workings and optimization algorithm are unknown [13]. In this study, it aims to use all renewables by replacing diesel with AD, which is a controllable renewable.

An optimal sizing method for wind-solar-battery hybrid system with stand-alone and grid-connected modes was proposed in [14]. A brute force technique is used to determine the optimal sizing by searching for the best combinations of the PV-windbattery while satisfying the proposed constraints. Loss of power supply probability and the fluctuation rate of the total output of renewable sources relative to the average load power were calculated for every probable combination. The optimal combination is chosen with minimum system cost. This method has a very high computation complexity and will scale up if detail sizing is required. A comparison of the sizing method has been made with HOMER, and the authors claimed the proposed approach has a higher computational cost. Generators have not been considered for the sizing purposes.

The technoeconomic feasibility studies of utilizing PVdiesel-battery hybrid systems to meet the load of a residential building, with an annual electrical demand of $35.12 \mathrm{MWh}$ and a commercial building with an annual electrical demand of $620 \mathrm{MWh}$ are presented in [15] and [16], respectively. HOMER software has been used to carry out the studies. It concluded that the hybrid system offers several benefits, such as PV penetration is high, load can be fulfilled in the optimal way, diesel maintenance can be minimized, and reliable power supply could be increased. The study uses monthly average daily solar global irradiance as input for the sizing purposes. The uncertainty aspect has not been included in the solar PV generation. The discount rate and financing costs have not been considered when performing the economic analysis.

An optimal sizing methodology for a stand-alone and grid connected PV-biomass hybrid energy system that serves the electricity demand of a typical village is presented in [17]. The results obtained shows that grid-connected hybrid system may be a cost-effective electrification solution for numerous villages in developing countries. However, in practice, it is impossible to be grid connected in numerous locations, especially for remote areas. Energy storage system should be employed to overcome this issue. The technical constraints from the biomass gasifier have not been considered in the study and also the average global solar irradiance was used for the study.

A study on optimal sizing of a hybrid wind-PV-diesel standalone power system is given in [18]. The consideration focused on the investment cost (installation and unit costs) and fuel cost minimization with constraints on the reliability requirement and $\mathrm{CO}_{2}$ emission limit. The output power of diesel generator ranges from $0 \mathrm{~kW}$ to the rated capacity; the technical and environmental constraints of diesel generator have been neglected in the study.

An algorithm for the economical design of a utility-scale photovoltaic power plant via compromising between the cost of energy and the availability of the plant was proposed in [19]. This paper introduces the effective levelized cost of energy (ELCOE) index as the core of the proposed design algorithm. ELCOE is an improved index based on the conventional LCOE that includes the availability of a power plant in economical assessments. However, the ELCOE proposed did not considered the use of storage systems.

\section{Study of Pyranometer Data}

\section{A. Solar Irradiance Data Acquisition}

The SKS 1110 Pyranometer sensor developed by Skye Instruments [20], [21] was used to collect the solar irradiance data for the study. The sensor consists of a semiconductor diode, cosine-corrected head and a light-filter system for the wavelength range $350-1100 \mathrm{~nm}$. Cosine-corrected head is built-in to eliminate measurement errors that may arise when the sun is not directly above the sensor, but at any angle within the hemisphere of measurement. The head is completely sealed and can be left indefinitely in exposed conditions in making it perfect for weather or energy balance studies. The sensor has been calibrated under open sky conditions against World Radiometric Reference [22].

The pyranometer sensor was mounted perfectly leveled, so that its top light collecting surface is exactly horizontal. The sensor is usually mounted in the same plane as the solar panel in order to measure the radiation falling on its surface. Four years of solar irradiance data between 2009 and 2012 were collected in Johannesburg for the study. The sampling rate is at 1 sample/30min.

\section{B. Solar Irradiance Data Analysis}

To determine the credibility of the irradiance data, a clear sky model [23] has been developed in MATLAB to provide comparisons. The Linke Turbidity Factor TLK has been set 


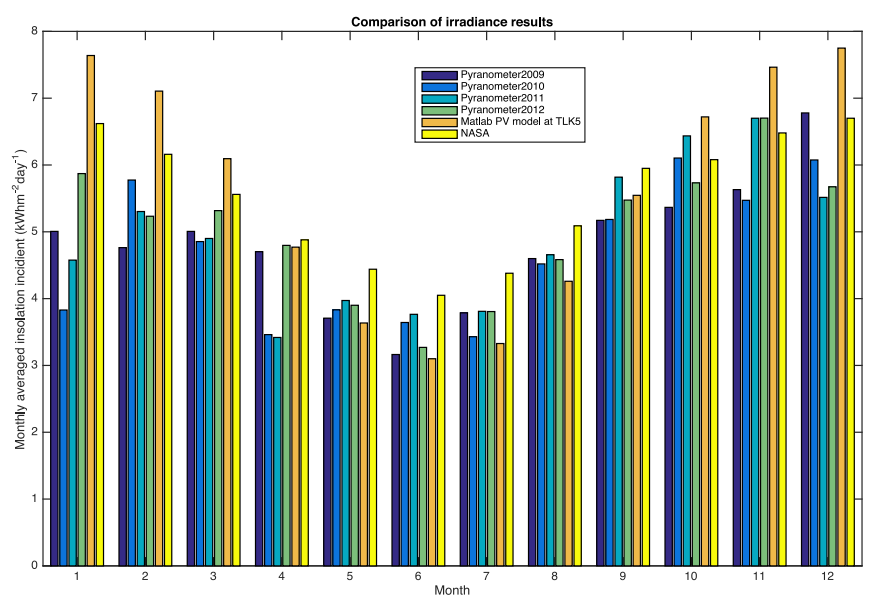

Fig. 1. Comparison of irradiance data.

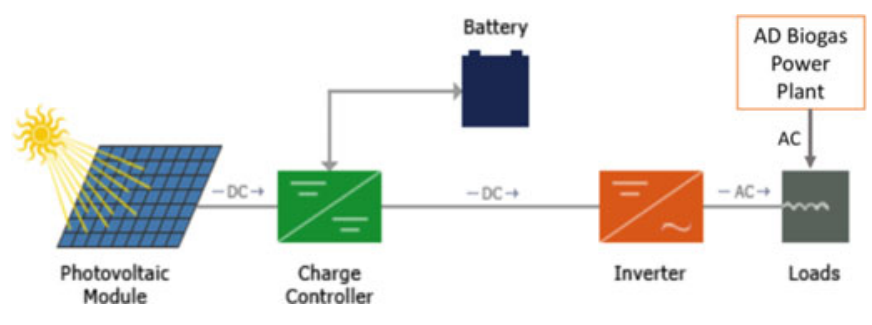

Fig. 2. Schematic diagram of the hybrid energy system.

to 5 to model the diffuse irradiance. A comparison of irradiance data from different sources are summarized in Fig. 1. Further comparisons are made with the NASA data obtained from [24]. The maximum amount of irradiance received is in December and the minimum amount is in June. The irradiance is generally higher in Summer (December, January, February) season as compared to other seasons.

The NASA and MATLAB models have a higher monthly averaged insolation incident because the study assumed to be clear sky condition. Therefore, there is a significant difference of results from pyranometer when compared to the two other sources. This could be due to the perturbation effect from the weather that affects the results of the pyranometer. The sources have a similar trend and this gives a good indication that the data are statistically correct.

\section{Optimal Sizing Problem}

\section{A. Context of the Sizing Problem}

Due to the diurnal stochastic effect of solar irradiance and the constraints from the BPP, the optimal sizing has become a complicated issue. A schematic figure of the hybrid system to be sized is shown in Fig. 2. The hybrid system aims to dispatch the maximum available solar power at each instantaneous time interval to meet the load demand. The problem arises when the solar power starts increasing and decreasing during the morning and afternoon, respectively; this will change the required output from the BPP.

A technical constraint for partial load operation of gas turbine power plants is the minimum emissions-compliant load

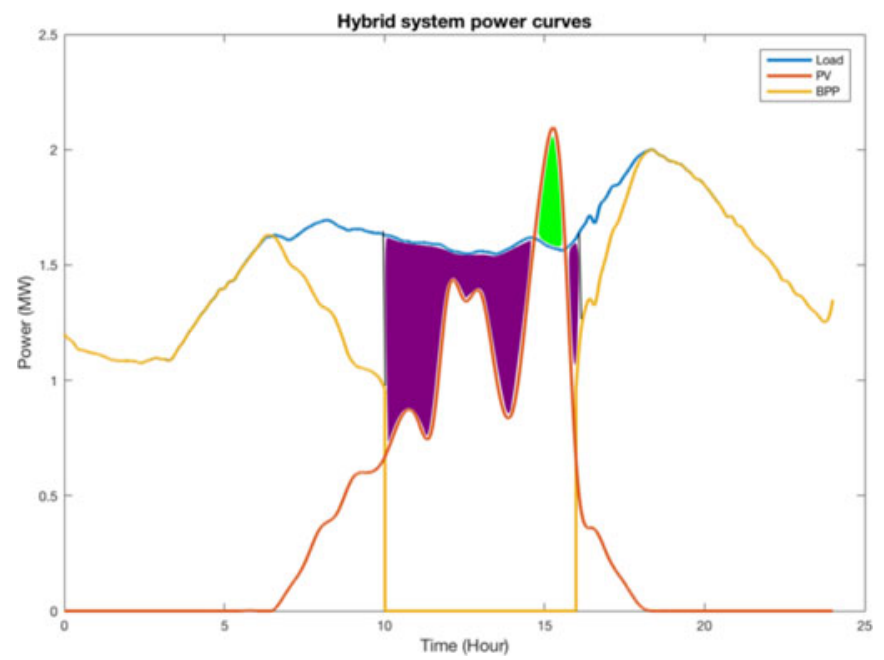

Fig. 3. Power curves of hybrid system.

(EMCL). This is the lowest output at which the gas turbine power plant can operate and still meet environmental limits for nitrous oxides $\left(\mathrm{N}_{2} \mathrm{O}\right)$ and carbon monoxide $(\mathrm{CO})$ emissions. Operation at lower loads can result in reduced combustion temperature, less conversion of $\mathrm{CO}$ to $\mathrm{CO}_{2}$, and potential emissions permit exceedances. The EMCL for most gas turbines is about $50 \%$ [25], [26] of full output.

To enable a wider range of gas turbine output, manufacturers have introduced control systems designed to extend emissionscompliant turndown while minimizing efficiency impacts at part-load. Part-load is when the generator is at some specified load value below $100 \%$ of its rated capacity. The approach is to produce higher combustion temperatures at low loads. Higher combustion temperatures not only enhance the conversion of $\mathrm{CO}$ to $\mathrm{CO}_{2}$, but also boost steam production and, thus, output from the steam turbine, improving overall part-load plant efficiency. As a result, some gas turbine models, such as (Siemens SGT6-5000F) [27], can achieve emissions-compliant turndown to about $40 \%$ of base load power [26], [28].

Additionally, if without enough cylinder pressure to maintain oil control at low loads, gas engines can develop ash deposits, a reduced detonation margin, and damaged engine components. Similar to diesel generator sets, deposit build up can occur on valves, spark plugs, and behind piston rings, which may cause cylinder liner polishing, power loss, poor performance, and accelerated component wear [29], [30].

In the afternoon, it is most likely there will be surplus energy. This energy should be stored and used to meet energy demands. In the late afternoon, the solar irradiance reduces and there is a need to increase the BPP output to meet the load. There are two occasions where there is not enough energy supply from both PV and BPP. BPP shuts down due to the operating constraint and not enough solar irradiance is available. Fig. 3 presents a typical solar power curve from real-life irradiance data, the BPP power from AD, and a downsized load curve. The BPP has been used to compensate the energy deficiency when solar energy is 
not available. The surplus and deficit energy are highlighted in green and purple, respectively.

\section{B. Optimization Problem Formulation and Methodology}

Without loss of generality, in this paper, optimal sizing is defined as the sizing to achieve the minimal LCOE. For the stand-alone hybrid renewable power system, this is achieved by determining the balance of energy supply and demand. When the system is oversized (surplus energy more than the deficit energy), energy wastage will occur and LCOE will increase. The undersized system will cause the energy imbalance issue and leads a high risk in power supply security.

The objective function is

$$
\min _{\text {area }}\left|E_{\text {Battery }}-E_{\text {Deficit }}\right|
$$

where

$$
E_{\text {Battery }}=E_{\text {Surplus }} \cdot \eta \text {. }
$$

$E_{\text {Battery }}$ is the energy produced from the PV system to be stored in storage system to meet $E_{\text {Deficit }}$ with round trip energy efficiency $\eta$ considered.

$$
E_{\text {Surplus }}=\int_{t=0}^{24} P_{\text {Surplus }} d t .
$$

$E_{\text {Surplus }}$ is the additional energy produced from the PV system. $P_{\text {Surplus }}$ is the instantaneous PV power subtracted by the instantaneous load demand when load demand is less than the $\mathrm{PV}$ power.

$$
E_{\text {Deficit }}=\int_{t=0}^{24} P_{\text {Deficit }} d t .
$$

$E_{\text {Deficit }}$ is the energy required from storage to meet the load that cannot be met by PV and $\mathrm{AD}$ during time $t . P_{\text {Deficit }}$ is the deficit power when no solar or AD power is available to support load demand. The constraints for the AD system are given as follows:

$$
\begin{aligned}
& P_{\mathrm{AD} m i n} \leq P_{\mathrm{AD}}(t) \leq P_{\mathrm{ADmax}} \\
& P_{\mathrm{ADmin}}=P_{\mathrm{ADmax}} * 0.4 \\
& P_{\mathrm{AD}}(t)=P_{\mathrm{Load}}(t)-P_{\text {Solar }}(t) .
\end{aligned}
$$

In this paper, it is assumed that BPP will not produce power when the power output drops below $40 \%$ of the rated capacity, as shown in (6). Equation (7) states that the output power from AD plant $P_{\mathrm{AD}}$ will be used to support the load demand after $P_{\text {Solar }}$ has reached the output capacity during time $t$. Reasonable assumptions have been made for case studies in this paper that the rated capacity of BPP, $P_{\mathrm{ADmax}}$, is at $2.4 \mathrm{MW}$ [31] with $\eta$ at $70 \%$ [32], [33]. The output power of solar panel $P_{\text {Solar }}$ is shown as

$$
P_{\text {Solar }}=\text { Irradiance }\left(\mathrm{Wm}^{-2}\right) * \text { Area }\left(\mathrm{m}^{2}\right) * \text { Efficiency }(\%) \text {. }
$$

\section{COMPARISON OF Optimization Methods}

To have a better intuition of the optimization problem, Fig. 4 shows a plot of the objective function and the variable to

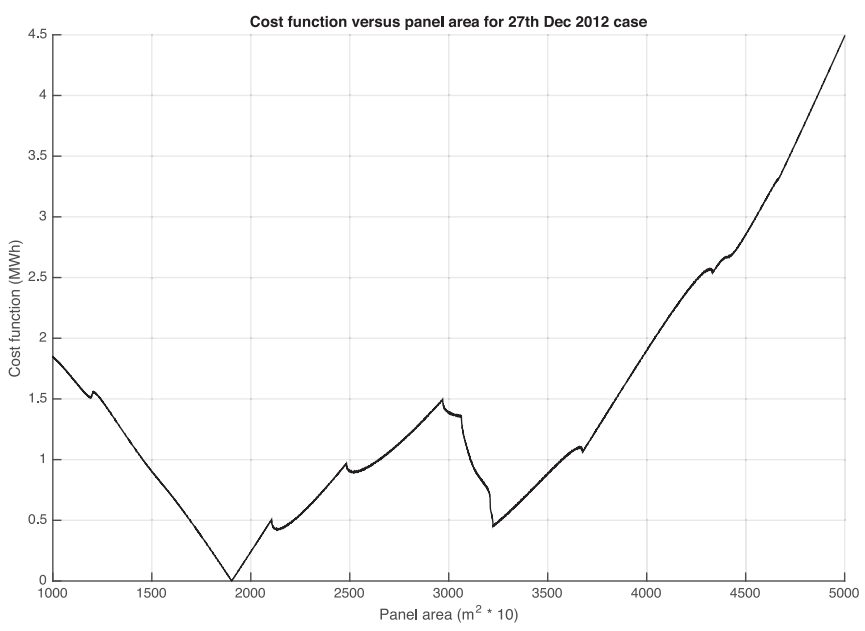

Fig. 4. Objective function with solar panel area variation for 27th December 2012 (LB case).

be minimized for a case on 27th December 2012. Initially, as not shown in the figure, the objective function is at minimum because the system's energy balance is achieved due to the enough deployment of AD power to support the load demand. As penetration of solar energy increases, AD will switch off due to the constraint given in (5)-(7).

The solar power curves used for the case studies are from the practical irradiance data and not the clear sky model, hence it contains perturbations. This will influence the switching of $\mathrm{AD}$ in an unsystematic manner. The cost function will become infinite as the panel areas approach infinity; this means there will be too much surplus energy. The optimization function is highly nonlinear with multiple local minima.

Seven different types of optimization techniques have been studied for the optimal sizing problem. These are interior point method (IP), pattern search (PS), genetic algorithm (GA), genetic algorithm with interior point method (GAIP), particle swarm optimization (PSO), particle swarm optimization with interior point method (PSOIP), and simulated annealing (SA). Two different search boundaries are used to study the optimization problem. The lower bound (LB) case is from 10000 to $50000 \mathrm{~m}^{2}$ and the upper bound (UB) case is from 50000 to $200000 \mathrm{~m}^{2}$. The reason for the LB to be $10000 \mathrm{~m}^{2}$ is to make sure that the hybrid system has a reasonable penetration of solar PV energy. For IP, SA, and PS, the initial point needs to be predefined. For this study, initial points are 30000 and 120000 for LB and UB cases, respectively.

The results for 17th, 21st, and 22nd in Fig. 5 are erroneous as the cost function values are high and the resulting panel area is at the search boundary, i.e., 10000 or $50000 \mathrm{~m}^{2}$. The $x$-axis represents the day for the daily case sizing and the $y$-axis is the cost function to be minimized. The optimal solution is not in the search boundary, hence the required panel area is significantly higher. This is due to the poor weather conditions of the day and the lack of solar irradiance. There is a requirement for more solar panels to provide enough solar energy. The majority of the results are similar with few cases where there are high discrepancies. The optimization results for 4th June 2012 have 

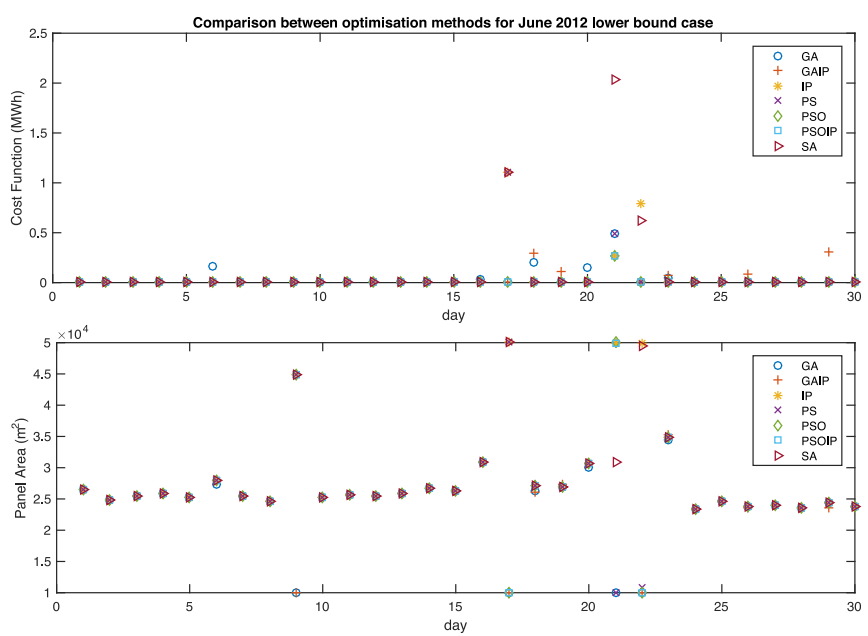

Fig. 5. PV system sizing for June 2012 LB case.
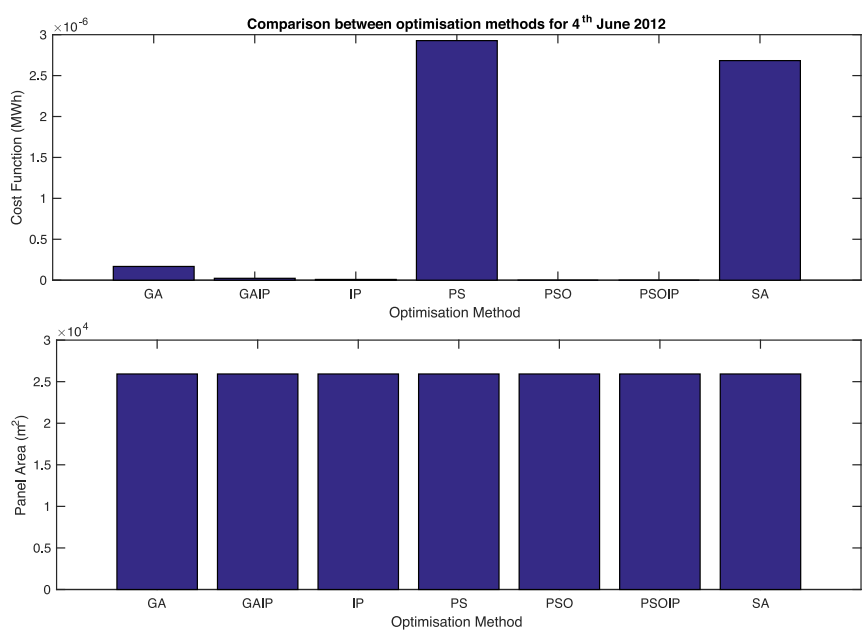

Fig. 6. Optimization method comparison for 4th June 2012.

been given in Fig. 6. It can be concluded that PSOIP has the lowest cost function value.

An UB case is used to size the solar panels for extreme weather conditions. Fig. 7 shows the results for June 2012 case. In the converse manner to Fig. 5, the cost function values are high for all days except for 17th, 21st, and 22nd. This signifies that there are feasible solutions for these days and the cost function can be minimized. The optimization results for 22nd June 2012 are shown in Fig. 8.

By considering the factors of minimal cost function value and the ability to reach global optimal, it can be concluded that PSOIP is the best candidate for this optimization problem. However, it should be noted that the choice of optimization algorithm is problem dependent as explained in [13].

\section{Optimization Procedure and Result}

The optimization process begins with data treatment and input of data to the optimization algorithm. Four years of solar
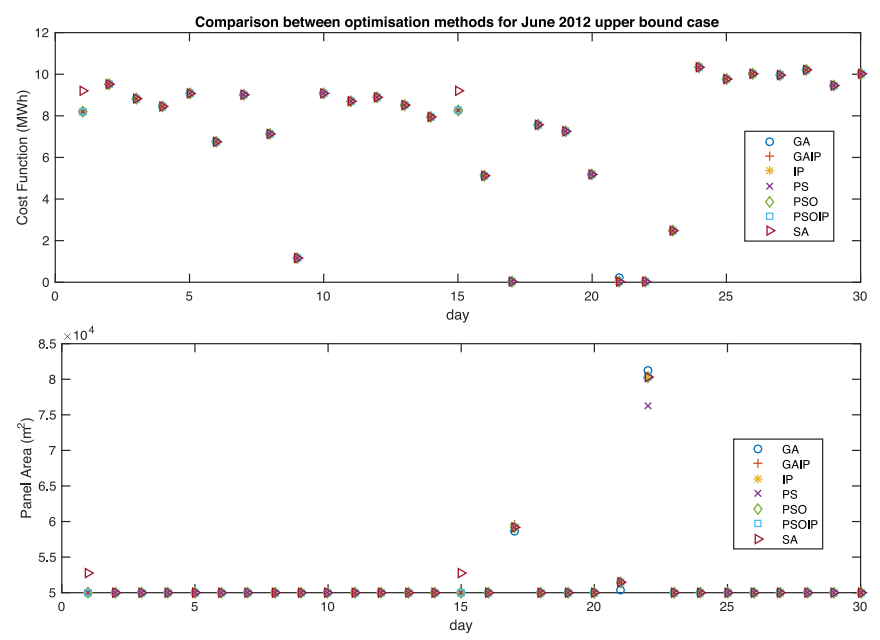

Fig. 7. PV system sizing for June 2012 UB case.
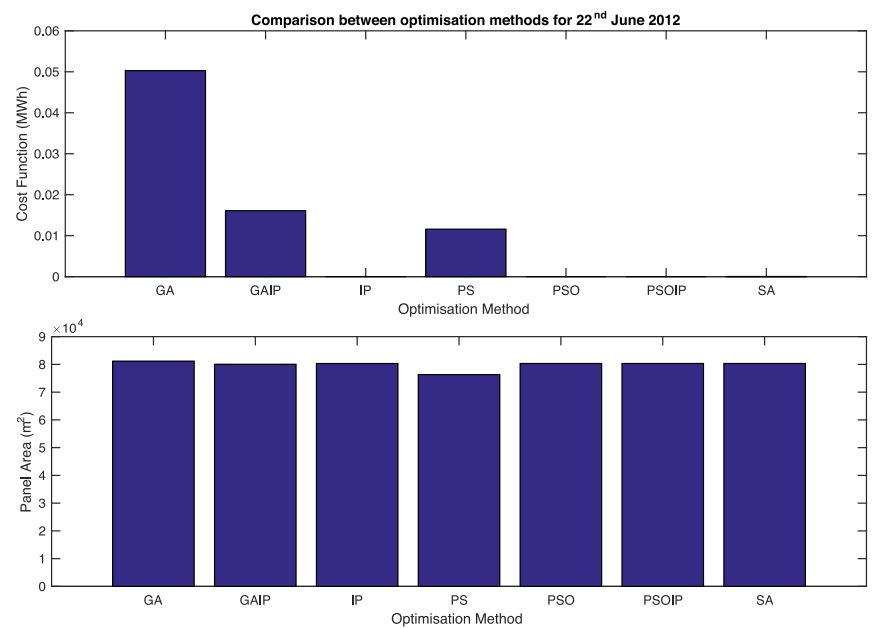

Fig. 8. Optimization method comparison for 22nd June 2012.

irradiance data have been segmented into individual days to determine the required panel area for each day. LB and UB cases are computed for each day. If there is a feasible solution in the UB, this result will be replaced in the LB result as this signifies that the required panel area is much higher. The four years of daily case optimization results are shown in Fig. 9. The red crosses in the box plot marks the "outliers" of the sizing results, and have a large contrast to the mean. The explanation of the outliers is due to the low solar irradiance on the day and the requirement of high panel area to produce enough surplus energy.

The search boundary needs to be divided into two known cases, namely, the LB case and UB case. As shown previously, this is because the search boundary is too large for the optimization algorithms to converge and to determine the correct optimal point. PSO parameters, such as the inertia range and minimum fraction neighbors, have been tuned for the optimization algorithm to give accurate results. The inertia range determines the contribution rate of a particle's previous velocity to its velocity 

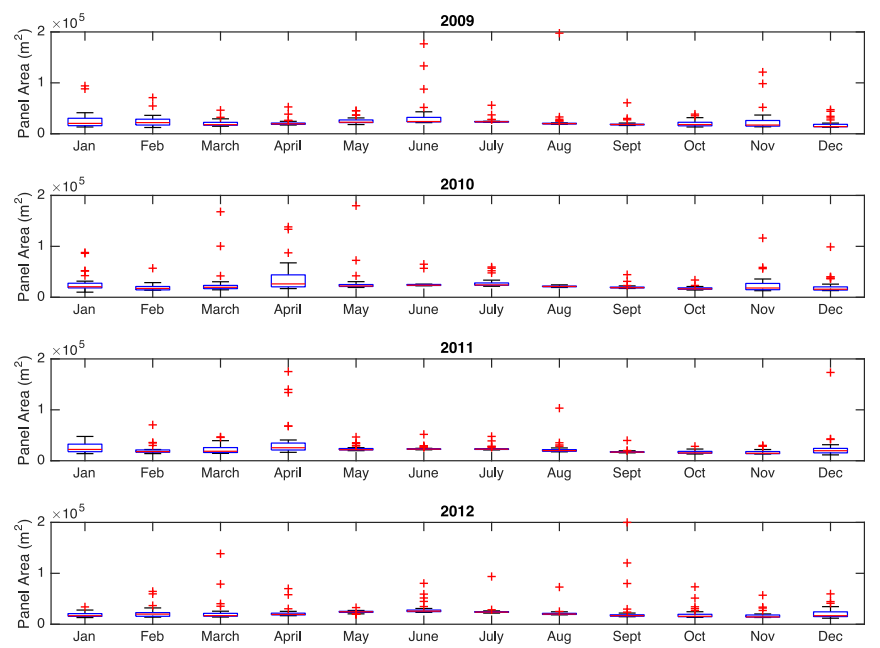

Fig. 9. Optimization results for the daily case PV system sizing.

TABLE I

AnNual CASE SizIng RESUlts

\begin{tabular}{ccc}
\hline \hline Year & Panel Area $\left(\mathrm{m}^{2}\right)$ & Rated capacity of PV Farm (MW) \\
\hline 2009 & 19770 & 4.95 \\
2010 & 19851 & 4.97 \\
2011 & 19468 & 4.87 \\
2012 & 19051 & 4.77 \\
\hline \hline
\end{tabular}

at the current time step. The proper selection of the neighborhood size affects PSO's tradeoff between exploration and exploitation, and unfortunately, there is no formal procedure to determine the optimal size. Table VIII of the Appendix in this paper gives the parameters and values for the PSO algorithm for the daily case sizing.

\section{COMPONENT SIZING OF HYBRID SYSTEM}

\section{A. Sizing of Solar Panels}

The solar panel to be used for the hybrid system is the Sharp ND-R250A5. It has an efficiency of $15 \%$ and has a rated power of $250 \mathrm{~W} /$ panel [34].

1) Annual Sizing Case Study: The daily solar irradiance profiles are connected as one annual profile for the annual sizing case study. The daily load curve is repeated according to the number of days in the annual case. The optimization is performed with PSOIP. Table I shows a consistent number of panels for the four years of data. It is safe to assume that the number of panels required is $20000 \mathrm{~m}^{2}$ and the system is equivalent to $5 \mathrm{MW}$. When compared to the daily sizing case, it can be seen that the annual sizing case gives a "smoothing effect" since it averages the load and solar data first before the optimization performs. The implications of the energy balance are less well understood with this sizing approach.

2) Daily Sizing Case Study: Due to the stochastic effect and inconsistent solar irradiance level in different seasons, it is impossible to determine the exact rated capacity of the solar farm to provide enough supply to the grid. It is impractical to

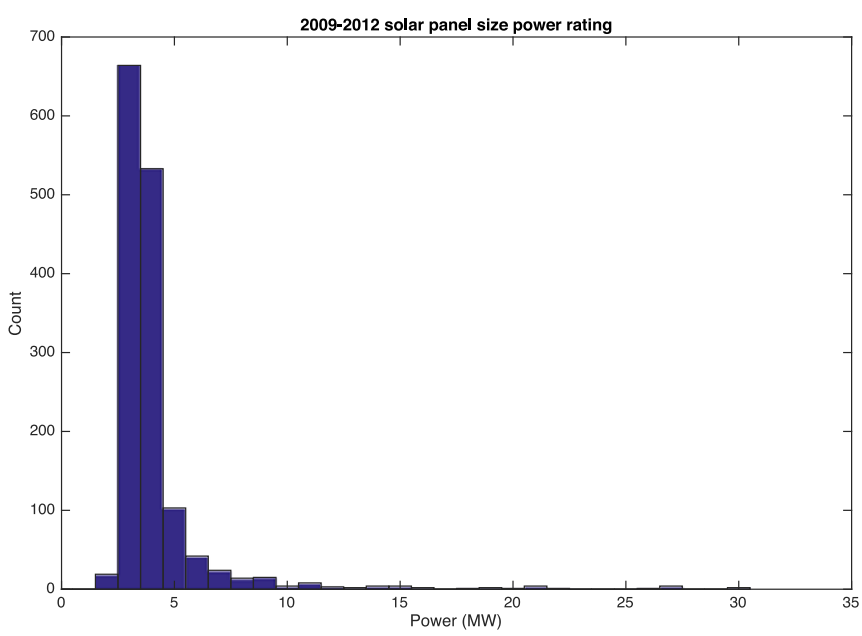

Fig. 10. Count for daily case solar panel sizing.

TABLE II

Percentage Day Covered at Different Power Ratings

Power rating (MW) Percentage for four years (\%) Accumulated percentage covered (\%)

\begin{tabular}{lcc}
\hline 2 & 1.304 & 1.304 \\
3 & 45.5731 & 46.8771 \\
4 & 36.582 & 83.4591 \\
5 & 7.0693 & 90.5284 \\
6 & 2.8826 & 93.411 \\
7 & 1.6472 & 95.0582 \\
$7+$ & 4.9418 & \\
\hline \hline
\end{tabular}

install a PV system that is capable of providing a solution to all events at all times; either the events would have to be very modest or the ESS is very large.

From Section VI, it is difficult to draw conclusion and insights from the box plot in Fig. 9. A method is proposed to determine the solar farm capacity by forming a histogram and considering the rated capacity of each day for the four years of data. The solar farm power rating for an individual day is calculated as

$$
P_{\text {SolarFarm day }}=P_{\text {Panel_rated }} * N_{\mathrm{PV}_{\text {day }}} \text {. }
$$

$\mathrm{N}_{\mathrm{PV}_{\text {dav }}}$ is the panel area for the given day and $\mathrm{P}_{\text {Panel_rated }}$ is the rated capacity of the PV panel. Fig. 10 shows the solar farm power rating for four years of daily case in a histogram plot calculated with (9). This effectively displays the probability distribution function for required sizing of the solar panels. The calculated value is then rounded up to the nearest positive infinity. Most of the required capacity is in the range of 2-6 MW with few case above $10 \mathrm{MW}$. This can be explained due to the poor weather and low irradiance. It will be uneconomical to size the PV system to provide solar energy to these extreme cases. The $\mathrm{AD}$ generator could be used to meet the energy requirement in this case.

Table II provides the percentage at different solar power rating. At $2 \mathrm{MW}$, only $1.304 \%$ of days in four years have enough solar energy supply and up to $90 \%$ of days are covered when the sizing is at $5 \mathrm{MW}$. The capital cost increases significantly by increasing the solar farm by a megawatt. 
TABLE III

MAXIMUM $E_{\text {Deficit }}$ FOR 2009-2012

\begin{tabular}{ccc}
\hline \hline Year & $E_{\text {Deficit }}(\mathrm{MWh})$ & $E_{\mathrm{PV}}(\mathrm{MWh})$ \\
\hline 2009 & 4.96 & 2.32 \\
2010 & 4.82 & 2.15 \\
2011 & 3.98 & 2.62 \\
2012 & 4.71 & 2.01 \\
\hline \hline
\end{tabular}
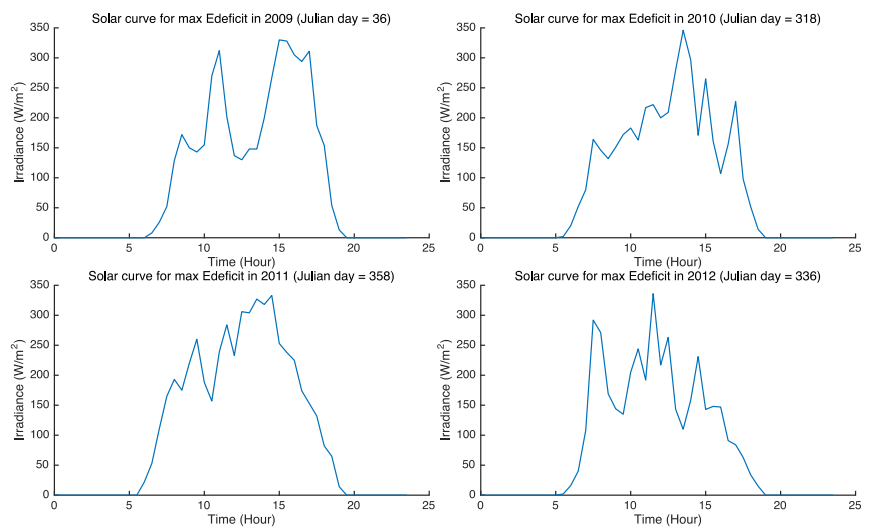

Fig. 11. Solar irradiance curves for 2009-2012 at maximum $E_{\text {Deficit }}$.

Since the total percentage cover increases slightly when above $5 \mathrm{MW}$ and by taking the daily and annual case sizing results into consideration, it can be concluded that $5 \mathrm{MW}$ is the best choice for sizing the solar farm. The deficit energy could be compensated by temporary running BPP at low efficiency.

\section{B. Sizing of Storage}

After the size of PV farm has been determined, $\mathrm{E}_{\text {Deficit }}$ is calculated for each day to determine the energy required to be stored in the storage system. Table III shows the results for $\mathrm{E}_{\text {Deficit }}$ with the maximum value for the corresponding year. It shows that in 2011, the deficit energy is significantly lower, and in 2009 has the highest deficit. Fig. 11 shows the solar irradiance curves with the Julian day number for the maximum $\mathrm{E}_{\text {Deficit }}$ during the daily sizing case. The irradiance curve for 2011 has less fluctuation compared to the other three years. This could reduce the number of switching of AD system and deficit energy could be reduced, resulting to a lower energy storage requirement.

The storage is to be sized at $5 \mathrm{MWh}$ by considering that the $\mathrm{E}_{\text {Deficit }}$ is under $5 \mathrm{MWh}$ for the four years of results.

\section{Sizing of Inverter and Controller}

The following constraints in (10) and (11) need to be fulfilled for the proposed hybrid system. The power output of total inverters and controllers need to be larger than the rated capacity of solar PV.

$$
\begin{aligned}
P_{\text {Inv }} N_{\text {Inv }} & \geq P_{\text {solar }} \\
P_{\text {Con }} N_{\text {Con }} & \geq P_{\text {solar }} .
\end{aligned}
$$

$\mathrm{P}_{\text {Inv }}$ and $\mathrm{P}_{\mathrm{Con}}$ are the rated power of the inverter and controller, respectively. $N_{\text {Inv }}$ and $N_{\text {Con }}$ are denoted for the number of inverters and controllers. For the hybrid system, the required number of inverters and controllers for the hybrid system is 1250 and 2500, respectively. The optimal sizing result for each component of the hybrid system is presented in Table IX of the Appendix.

\section{LeVelized Cost of Energy}

LCOE is a measure of costs that attempts to compare different methods of electricity generation on a comparable basis. It is an economic assessment of the average total cost to build and operate a power-generating asset over its lifetime divided by the total energy output of the asset over that lifetime.

The economic projections on complex hybrid systems utilizing these three technologies is challenging and no comprehensive method is available for guiding decision makers [35]. The authors claimed to have provided a new method of quantifying the economic viability of off-grid PV-battery-CHP systems by calculating the LCOE of the technology to be compared to centralized grid electricity. The proposed LCOE for the hybrid system is given as follows [35]:

$$
\mathrm{LCOE}=\frac{\mathrm{I}+\sum_{t=1}^{n} \frac{\left(I * i+O+F_{\mathrm{chp}}\right)}{(1+r)^{t}}}{\sum_{t=1}^{n} E_{\mathrm{tpv}}\left(1-d_{1}\right)^{t}+\frac{E_{\mathrm{tchp}}\left(1-d_{2}\right)^{t}}{(1+r)^{t}}} .
$$

Here, $n$ is the lifetime of the hybrid system in years, $r$ is the discount rate on the hybrid system per year, I is the total installation cost, which includes the cost of solar PV, battery, and the CHP module, $i$ is the interest rate on the hybrid system for $100 \%$ debt financing. $O$ is the total operation and maintenance cost. $F_{\text {chp }}$ is the annual fuel cost of the CHP unit. $E_{\mathrm{tpv}}$ and $E_{\text {tchp }}$ are the rated annual energy production from solar PV and CHP

units, respectively. $d_{1}$ and $d_{2}$ are the degradation rates for solar PV and CHP units, respectively. The energy produced by the PV system is not discounted. It does not reflect the actual value of the solar PV energy in the future. Cost implication due to storage has not been included in the analysis in detail. Although storage does not generate energy, the total energy production will be affected by storage due to round trip efficiency. This section of the paper presents the cost calculation of the sys-tem and comparisons for two different systems will be made. Table IV gives the cost specification of the components for the hybrid system.

The general equation for LCOE [39] is given in (13). The cost and energy calculation of the system components are given in (14)-(22)

$$
\begin{aligned}
\text { LCOE } & =\frac{\text { Lifecycle cost }(\$)}{\text { Lifetime energy production }(\mathrm{kWh})} \\
C_{\text {Redox }} & =C_{\text {cap_ESS }}+\sum_{t=0}^{n} \frac{C_{\text {O\&__EESS }_{t}}}{(1+r)^{t}} \\
E_{\mathrm{ESS}} & =\eta \sum_{t=0}^{n} \frac{E_{\text {surplus }_{t}\left(1-D_{\text {Redox }}\right)^{t}}}{(1+r)^{t}}
\end{aligned}
$$


TABLE IV

COST SPECIFICATION

\begin{tabular}{|c|c|c|c|c|c|}
\hline & $\begin{array}{c}\text { PV (Sharp } \\
\text { ND-250QCS) }\end{array}$ & $\begin{array}{c}\text { Vanadium } \\
\text { Redox Flow } \\
\text { battery (VRB) }\end{array}$ & AD BPP & $\begin{array}{c}\text { Inverter } \\
\text { (Schneider } \\
\text { Electric } \\
\text { XW4024) }\end{array}$ & $\begin{array}{c}\text { Controller } \\
\text { (Outback FM } \\
80)\end{array}$ \\
\hline $\begin{array}{l}\text { Capital cost } \\
\text { (cap) }\end{array}$ & $\begin{array}{c}120 \text { (\$/unit) } \\
\text { [34], [36] }\end{array}$ & $\begin{array}{c}760-1600 \\
(\$ / \mathrm{kWh})[32] \\
{[33]}\end{array}$ & $\begin{array}{c}\$ 7.5 \mathrm{M}[31] \\
{[37]}\end{array}$ & $\begin{array}{c}812.05 \text { (\$/unit) } \\
{[34]}\end{array}$ & $\begin{array}{c}335 \text { (\$/unit) } \\
{[34]}\end{array}$ \\
\hline $\begin{array}{l}\text { Install-ation } \\
\text { cost (inst) }\end{array}$ & $\begin{array}{c}108 \text { (\$/unit) } \\
{[34]}\end{array}$ & N/A & N/A & $\begin{array}{c}24.2386 \\
\text { (\$/unit) [34] }\end{array}$ & $\begin{array}{c}6.7 \text { (\$/unit) } \\
{[34]}\end{array}$ \\
\hline $\begin{array}{l}\mathrm{O} \& \mathrm{M} \text { cost } \\
(\mathrm{O} \& \mathrm{M})\end{array}$ & $\begin{array}{c}6(\$ / \text { unit/ } \\
\text { ye-ar) [34] }\end{array}$ & $\begin{array}{c}100-140 \\
(\$ / \mathrm{kWh})[33]\end{array}$ & $\begin{array}{c}350(\$ / \mathrm{kW}) \\
{[38]}\end{array}$ & $\begin{array}{c}2.43615 \\
\text { (\$/unit/ye-ar) } \\
{[34]}\end{array}$ & $\begin{array}{c}1.005 \\
\text { (\$/unit/ye-ar) } \\
{[34]}\end{array}$ \\
\hline
\end{tabular}

$$
\begin{aligned}
& C_{\text {pvsurplus }}=\left(C_{\text {cap_pv }}+C_{\text {inst_pv }}+\sum_{t=0}^{n} \frac{C_{{\mathrm{O} \& \mathrm{M}_{\text {_pv }}}_{t}}}{(1+r)^{t}}\right. \\
& \times N_{\text {pvsurplus }} \\
& C_{\text {pvdirect }}=\left(C_{\text {cap_pv }}+C_{\text {inst_pv }}+\sum_{t=0}^{n} \frac{C_{{\mathrm{O} \& \mathrm{M}_{-} \mathrm{pv}_{t}}}}{(1+r)^{t}}\right. \\
& \times N_{\text {pvdirect }} \\
& E_{\text {pvdirect }}=\sum_{t=0}^{n} \frac{\left(E_{\text {direct }_{t}}\right)\left(1-D_{\mathrm{pv}}\right)^{t}}{(1+r)^{t}} \\
& C_{\mathrm{AD}}=C_{\mathrm{capAD}}+\sum_{t=0}^{n} \frac{C_{\mathrm{O} \& \mathrm{M} \_\mathrm{AD} t}}{(1+r)^{t}} \\
& E_{\mathrm{AD} \_ \text {total }}=\sum_{t=0}^{n} \frac{E_{\mathrm{AD} t}}{(1+r)^{t}} \\
& C_{\text {Inv }}=\left(C_{\text {capinv }}+C_{\text {instinv }_{\text {in }}}+\sum_{t=0}^{n} \frac{C_{\mathrm{O}_{t} \mathrm{M}_{\mathrm{inv}_{t}}}}{(1+r)^{t}} \quad N_{\mathrm{inv}}\right.
\end{aligned}
$$

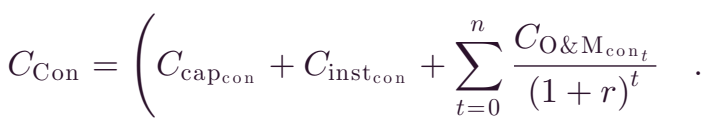

In this study, the lifetime of the hybrid system is assumed to be 20 years, with storage system degradation rate $D_{\text {Redox }}$ at $0.1 \%$ per year [40] and PV panel degradation rate $D_{\mathrm{PV}}$ at $0.05 \%$ [19], [41]. There is an inverter lifetime extension to at least 20 years of full operation by 2013 and 30 years by 2020 [8]. The controllers and inverters are assumed to be replaced once during the lifetime of the system, and the replacement cost is the same as the capital cost [34]. $N_{\text {pvdirect }}, N_{\text {pvsurplus }}, N_{\text {Inv }}$, and $N_{\text {Con }}$ are the number of units of PV panels for generating energy for direct consumption, surplus energy for storage, inverters, and controllers, respectively. $E_{\text {direct }}$ is the energy generated from PV and directly supplied to the load without going through storage. $\mathrm{E}_{\mathrm{AD} \text { _total }}$ is the total lifetime energy output from BPP powered by AD. $C_{\text {pvsurplus }}$ and $C_{\text {pvdirect }}$ are the total lifetime costs of $\mathrm{PV}$ generation that produce the surplus and direct consumption of energy for the system, respectively.
TABLE V

AD-ONLY CASE

\begin{tabular}{lc}
\hline \hline$r(\%)$ & LCOE $_{\text {system }}(\$ / \mathrm{kWh})$ \\
\hline 2 & 0.383 \\
8 & 0.403 \\
10 & 0.409 \\
15 & 0.427 \\
\hline \hline
\end{tabular}

\section{A. Levelized Cost of Delivery (LCOD)}

The term levelized cost of storage (LCOS) was explored in [42], which is solely used for comparing storage technologies. The equation is of similar nature to LCOE. The LCOD is proposed to compare the cost effectiveness of storage for the system [43]. The LCOD is given as follows:

$$
\mathrm{LCOD}=\frac{\sum_{t=0}^{n} \frac{C_{\mathrm{in}_{t}}}{(1+r)^{t}}}{\eta \sum_{t=0}^{n} \frac{E_{\mathrm{in}_{t}}}{(1+r)^{t}}}+\frac{\sum_{t=0}^{n} \frac{C_{\mathrm{ESS}_{t}}}{(1+r)^{t}}}{\eta \sum_{t=0}^{n} \frac{E_{\mathrm{in}_{t}}}{(1+r)^{t}}} .
$$

By splitting (23) into two individual components, the final form of LCOE for the ESS is given as

$$
\mathrm{LCOD}=\frac{1}{\eta} \operatorname{LCOE}\left(E_{\text {surplus }}\right)+\text { LCOS. }
$$

In practice, the energy flowing into ESS, $E_{\text {in }}$, will be the surplus energy $E_{\text {surplus }}$. The cost of storing the surplus energy into ESS, $C_{\mathrm{in}}$, will be $C_{\mathrm{pvsurplus}}$ plus the cost of the controller $C_{\mathrm{Con}}$.

\section{B. LCOE for System}

For a hybrid renewable and storage power system, the following LCOE relationship will hold:

$$
\operatorname{LCOE}_{\text {system }}=\frac{\sum_{t=0}^{n} \frac{C_{\text {system }_{t}}}{(1+r)^{t}}}{\sum_{t=0}^{n} \frac{E_{\text {system }}}{(1+r)^{t}}} .
$$

$C_{\text {system }_{t}}$ and $E_{\text {system }_{t}}$ are the total cost and total energy production from the system at year $t$, respectively. The total cost of the renewable system is the sum of PV, BPP generation, power conversion, and storage costs. The total energy produced by the system is the energy output of ESS, the energy directly delivered to the load by PV, and the energy produced by BPP to support the energy deficit. Therefore, the LCOE for the system is given as

$$
\begin{aligned}
& \mathrm{LCOE}_{\text {system }} \\
& =\frac{C_{\text {pvsurplus }}+C_{\text {Redox }}+C_{\text {pvdirect }}+C_{\mathrm{AD}}+C_{\text {Inv }}+C_{\text {Con }}}{E_{\text {ESS }}+E_{\text {pvdirect }}+E_{\mathrm{AD} \_ \text {total }}} .
\end{aligned}
$$

\section{Cost Analysis for PV Hybrid and AD-Only Systems}

The LCOE at different discount rates $2 \%, 8 \%, 10 \%$, and $15 \%$ are studied for three case studies and the results are presented in Tables V-VII. The AD-only system is a microgrid system that generates energy solely by BPP, with no PV, ESS, inverter, and controller installed. The hybrid system is the microgrid proposed in Fig. 3. Storage is an expensive component and also the energy 
TABLE VI

HYBRID SYSTEM WITH VRB AT LB COST

\begin{tabular}{lcccccccc}
\hline \hline $\mathrm{r}(\%)$ & \multicolumn{3}{c}{ LCOD $(\$ / \mathrm{kWh})$} & \multicolumn{5}{c}{ LCOE $_{\text {system }}(\$ / \mathrm{kWh})$} \\
\hline & 2009 & 2010 & 2011 & 2012 & 2009 & 2010 & 2011 & 2012 \\
2 & 0.83 & 0.89 & 0.80 & 0.74 & 0.34 & 0.35 & 0.34 & 0.34 \\
8 & 1.16 & 1.24 & 1.11 & 1.03 & 0.39 & 0.40 & 0.39 & 0.39 \\
10 & 1.28 & 1.36 & 1.23 & 1.13 & 0.41 & 0.42 & 0.41 & 0.41 \\
15 & 1.58 & 1.69 & 1.52 & 1.41 & 0.55 & 0.46 & 0.42 & 0.45 \\
\hline \hline
\end{tabular}

TABLE VII

HYBRID SYSTEM WITH VRB AT UB COST

\begin{tabular}{lcccccccc}
\hline \hline$r(\%)$ & \multicolumn{3}{c}{ LCOD $(\$ / \mathrm{kWh})$} & \multicolumn{5}{c}{ LCOE $_{\text {system }}(\$ / \mathrm{kWh})$} \\
\hline & 2009 & 2010 & 2011 & 2012 & 2009 & 2010 & 2011 & 2012 \\
2 & 1.21 & 1.30 & 1.17 & 1.07 & 0.36 & 0.37 & 0.36 & 0.36 \\
8 & 1.76 & 1.88 & 1.68 & 1.55 & 0.42 & 0.43 & 0.42 & 0.42 \\
10 & 1.95 & 2.08 & 1.87 & 1.73 & 0.44 & 0.45 & 0.44 & 0.44 \\
15 & 2.46 & 2.63 & 2.36 & 2.18 & 0.50 & 0.51 & 0.50 & 0.49 \\
\hline \hline
\end{tabular}

stored in general is a small proportion as compared to generated energy, so the ratio between battery cost to its amount of stored energy will be bigger as compared to that $\mathrm{LCOE}_{\mathrm{system}}$. This is the reason that LCOD is significantly higher than the LCOE of the system. Using sensitivity analysis, the cross-over point for the system's LCOE can be determined. The results show that by considering the Redox storage at LB cost, the hybrid system could be cheaper than running an AD-only system when the discount rate is below $8 \%$. At higher bound cost, the discount rate needs to be below $2 \%$.

As reported in [33], the LCOS for Redox storage system in a renewable energy system integration is between 0.373 and 0.950 $\$ / \mathrm{kWh}$, with discount rate at $8 \%$. Since there is a fixed cost, i.e., capital and installation costs, and while both variable cost and energy are affected equally by discount rate, therefore LCOS increases as discount rate increases. The LCOD of the system is much higher than LCOS when the cost of storing the energy is included. As reported in [44], the current discount rate for solar $\mathrm{PV}$ and $\mathrm{AD}$ is $6-9 \%$ and $7-10 \%$, respectively. The discount rate for technologies that are supported by a policy could be as much as $2-3 \%$ lower over the next decade, and could fall by a further $1-2 \%$ by 2040 . The LCOE for the hybrid system in this paper has been given the assumption that the capital cost of PV will be reduced by $50 \%$ as compared to that for PV system in [34] due to Swanson's law [36]. At high discount rates, capital-intensive generation sources, such as $\mathrm{PV}$, are at a disadvantage due to the value of energy and money is lower in the future.

In general, AD-only system can have a smaller LCOE but may be different for smaller discount rate. This is likely to be the future trend. If there are incentivizes, for example, for equipment cost, there could be a reduction in capital cost and as such, it could be better to have a hybrid system as this leads to a lower LCOE.

\section{CONCLUSION AND FUtURE WORK}

This paper proposed a sizing methodology with deterministic approach for a stand-alone high-penetration PV system with support from ESS and AD BPP. The costs had been calculated with the proposed LCOE methods and it showed that the hybrid energy system could be more economical than using a standalone AD BPP when discount rate dropped below $8 \%$ with the current technology costs.

In this paper, the load curve was assumed to be the same for all days in the year due to the users had a consistent consumption in the small community. Future studies could consider when the load is irregular or less than the minimum AD output power. The conventional approach to sizing the power system is to use the cost of energy as the objective function. This approach could also be studied and comparisons could be made as future work. State of charge, depth of discharge, and state of health of battery need to be considered. This is another focus for the future work.

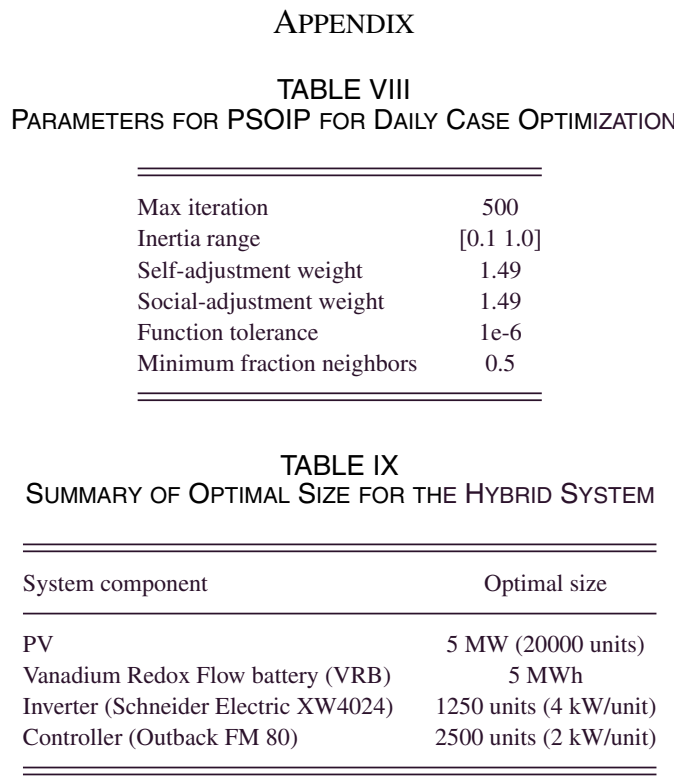

\section{REFERENCES}

[1] International Energy Agency, "World energy outlook," 2012. [Online]. Available: http://www.worldenergyoutlook.org/media/weowebsite/energ ydevelopment/2012updates/measuringprogresstowardsenergyforall_weo 2012.pdf. Accessed on: May 16, 2016.

[2] U.S. Dept. Energy, "DOE announces $\$ 87$ million in funding to support solar energy technologies," 2009. [Online]. Available: http://energy.gov/ articles/doe-announces-87-million-funding-support-solar-energy-technologies. Accessed on: May 16, 2016.

[3] Energy Research Institute National Development and Reform Commission, "China 2050 high renewable energy penetration scenario and roadmap study," 2015. [Online]. Available: http://www.efchina. org/Attachments/Report/report-20150420/China-2050-High-RenewableEnergy-Penetration-Scenario-and-Roadmap-Study-Executive-Summary. pdf. Accessed on: May 16, 2016.

[4] Indian power sector.com, "Jawaharlal Nehru national solar mission targets 20,000MW by 2022.," [Online]. Available: http://indianpowersector. com/electricity-regulation/national-solar-mission. Accessed on: May 16, 2016.

[5] N. K. Sharma, P. K. Tiwari, and Y. R. Sood, "Solar energy in India: Strategies, policies, perspectives and future potential," Renewable Sustain. Energy Rev., vol. 16, pp. 933-941, Jan. 2012.

[6] T. Strasser et al., "A review of architectures and concepts for intelligence in future electric energy systems," IEEE Trans. Ind. Electron., vol. 62, no. 4, pp. 2424-2438, Apr. 2015.

[7] J. M. Carrasco et al., "Power-electronic systems for the grid integration of renewable energy sources: A survey," IEEE Trans. Ind. Electron., vol. 53, no. 4, pp. 1002-1016, Jun. 2006.

[8] G. Petrone, G. Spagnuolo, R. Teodorescu, M. Veerachary, and M. Vitelli, "Reliability issues in photovoltaic power processing systems," IEEE Trans. Ind. Electron, vol. 55, no. 7, pp. 2569-2580, Jul. 2008. 
[9] J. L. Bernal-Agustín and R. Dufo-López, "Simulation and optimization of stand-alone hybrid renewable energy systems," Renew. Sustain. Energy Rev., vol. 13, pp. 2111-2118, Oct. 2009.

[10] S. H. El-Hefnawi, "Photovoltaic diesel-generator hybrid power system sizing," Renew. Energy, vol. 13, pp. 33-40, Jan. 1998.

[11] S. Rehman and L. M. Al-Hadhrami, "Study of a solar PV-diesel-battery hybrid power system for a remotely located population near Rafha, Saudi Arabia," Energy, vol. 35, pp. 4986-4995, Dec. 2010.

[12] Homer Energy. [Online]. Available: http://www.homerenergy.com/ software.html. Accessed on: Aug. 20, 2016.

[13] O. Erdinc and M. Uzunoglu, "Optimum design of hybrid renewable energy systems: Overview of different approaches," Renew. Sustain. Energy Rev., vol. 16, pp. 1412-1425, Apr. 2012.

[14] L. Xu, X. Ruan, C. Mao, B. Zhang, and Y. Luo, "An improved optimal sizing method for wind-solar-battery hybrid power system," IEEE Trans. Sustain. Energy, vol. 4, no. 3, pp. 774-785, Jul. 2013.

[15] S. Shaahid and M. Elhadidy, "Economic analysis of hybrid photovoltaicdiesel-battery power systems for residential loads in hot regions-A step to clean future," Renew. Sustain. Energy Rev., vol. 12, pp. 488-503, Feb. 2008.

[16] S. Shaahid and M. Elhadidy, "Technical and economic assessment of grid-independent hybrid photovoltaic-diesel-battery power systems for commercial loads in desert environments," Renew. Sustain. Energy Rev., vol. 11, pp. 1794-1810, Oct. 2007.

[17] S. Singh and S. C. Kaushik, "Optimal sizing of grid integrated hybrid PVbiomass energy system using artificial bee colony algorithm," IET Renew. Power Gener, vol. 10, pp. 642-650, May 2016.

[18] Y.-Y. Hong and R.-C. Lian, "Optimal sizing of hybrid wind/PV/diesel generation in a stand-alone power system using Markov-based genetic algorithm," IEEE Trans. Power Del., vol. 27, no. 2, pp. 640-647, Apr. 2012.

[19] Z. Moradi-Shahrbabak, A. Tabesh, and G. R. Yousefi, "Economical design of utility-scale photovoltaic power plants with optimum availability," IEEE Trans. Ind. Electron., vol. 61, no. 7, pp. 3399-3406, Jul. 2014

[20] Skye Instruments, Ltd., "SKS 1110 Pyranometer.," [Online]. Available: http://www.skyeinstruments.info/index_htm_files/Pyranometer.pdf. Accessed on: Aug. 25, 2016.

[21] Skye Instruments, Ltd., "Solar radiation system for photo voltaics," 2009. [Online]. Available: http://www.skyeinstruments.info/index_htm_files/ Solar Radiation Syst. Photovoltaics.pdf. Accessed on: Aug. 25, 2016.

[22] I. Rüedi and W. Finsterle, "The world radiometric reference and its quality system," in Proc. WMO Tech. Conf. Meteorol. Environ. Instrum. Methods Obs., Instrum. Obs. Methods, Bucharest, Romania, 2005, pp. 434-436.

[23] K. Scharmer and J. Greif, The European Solar Radiation Atlas Vol. 1: Fundamentals and Maps. Paris, France: Ècole des Mines de Paris, 2000.

[24] "NASA surface meteorology and solar energy.," [Online]. Available: https://eosweb.larc.nasa.gov/cgi-bin/sse/grid.cgi. Accessed on: Mar. 12, 2016

[25] B. M. Igoe, "Dry low emissions experience across the range of Siemens small industrial gas turbines," Siemens Ind. Turbomach. Ltd., Lincoln, U.K., [Online]. Available: http://www.energy.siemens. com/nl/pool/hq/energy-topics/pdfs/en/techninal\%20paper/Dry\%20Low\% 20Emissions\%20Experience.pdf. Accessed on: Aug. 23, 2016.

[26] Wartsila, "Combustion engine vs. gas turbine: Part load efficiency and flexibility," [Online]. Available: http://www.wartsila.com/energy/learningcenter/technical-comparisons/combustion-engine-vs-gas-turbine-partload-efficiency-and-flexibility. Accessed on: Aug. 25, 2016

[27] Siemens, "Reliable and powerful economical, safe-investment packages SGT6-PAC 5000F / SCC6-PAC 5000F," 2015. [Online]. Available: http://www.energy.siemens.com/hq/pool/hq/power-generation/gasturbines/SGT6-5000F/SGT6-5000FPAC_LowRes.pdf. Accessed on: Aug. 25, 2016.

[28] TMI Staff \& Contributors, "Design and operating considerations for combined cycle plants," Turbomach. Mag., 2011. [Online]. Available: https://www.turbomachinerymag.com/design-and-operatingconsiderations-for-combined-cycle-plants/. Accessed on: Aug. 25, 2016].

[29] B. Jabeck, "The impact of generator set underloading," Caterpillar, Inc., 2015. [Online]. Available: https://forums.cat.com/t5/BLOG-PowerPerspectives/The-Impact-of-Generator-Set-Underloading/ba-p/69719. Accessed on: Aug. 25, 2016

[30] Noria Corporation, "Lubricating natural gas engines," Mach. Lubrication. [Online]. Available: http://www.machinerylubrication.com/Read/ 29018/natural-gas-engines. Accessed on: Aug. 25, 2016.

[31] R\&D Construction, Ltd., "R\&D wins renewable project for a 2.4 megawatt anaerobic digestion plant.," [Online]. Available: http://www. randdconstruction.co.uk/rd-wins-renewable-project-for-a-2-4-megawattanaerobic-digestion-plant. Accessed on: Mar. 1, 2016.
[32] X. Luo, J. Wang, M. Dooner, and J. Clarke, "Overview of current development in electrical energy storage technologies and the application potential in power system operation," Appl. Energy, vol. 137, pp. 511536, Jan. 2015

[33] Lazard, "Lazard's levelized cost of storage analysis V1.0," 2015. [Online]. Available: https://www.lazard.com/media/2391/lazardslevelized-cost-of-storage-analysis-10.pdf. Accessed on: Apr. 15, 2016.

[34] A. Hassan, M. Saadawi, M. Kandil, and M. Saeed, "Modified particle swarm optimisation technique for optimal design of small renewable energy system supplying a specific load at Mansoura University," IET Renew. Power Gener, vol. 9, pp. 474-483, Jul. 2015.

[35] A. S. Mundada, K. K. Shah, and J. Pearce, "Levelized cost of electricity for solar photovoltaic, battery and cogen hybrid systems," Renew. Sustain. Energy Rev., vol. 57, pp. 692-703, May 2016.

[36] R. M. Swanson, "A vision for crystalline silicon photovoltaics," Progr Photovoltaics, Res. Appl., vol. 14, pp. 443-453, Aug. 2006.

[37] The Association for Decentralised Energy, "First AD biogas plant opens in Kenya," 2015. [Online]. Available: http://www.theade.co.uk/firstadbiogas-plant-opens-in-kenya_3412.html. Accessed on: Mar. 18, 2016.

[38] National Renewable Energy Laboratory, "CREST cost of energy model: anaerobic digestion V1.4.," [Online]. Available: https://financere.nrel.gov/ finance/content/crest-cost-energy-models. Accessed on: Mar. 18, 2016.

[39] S. B. Darling, F. You, T. Veselka, and A. Velosa, "Assumptions and the levelized cost of energy for photovoltaics," Energy Environ. Sci., vol. 4 pp. 3133-3139, Sep. 2011.

[40] I. Pawel, "The cost of storage-How to calculate the levelized cost of stored energy (LCOE) and applications to renewable energy generation," Energy Procedia, vol. 46, pp. 68-77, 2014.

[41] National Renewable Energy Laboratory, "CREST cost of energy model: photovoltaic V1.4.," [Online]. Available: https://financere.nrel.gov/ finance/content/crest-cost-energy-models. Accessed on: Mar. 18, 2016.

[42] World Energy Resources, "E-storage: Shifting from cost to value wind and solar applications," World Energy Council, London, U.K., 2016.

[43] C. S. Lai and M. D. McCulloch, "Levelized cost of energy for PV and grid scale energy storage systems," ArXiv preprint, arXiv: 1609.06000, Sep. 2016.

[44] Prepared for the committee on climate change, "Discount rates for lowcarbon and renewable generation technologies," Oxera, 2011. [Online]. Available: http://www.oxera.com/Latest-Thinking/Publications/Reports/ 2011/Discount-rates-for-low-carbon-and-renewable-genera.aspx. Accessed on: Mar. 15, 2016

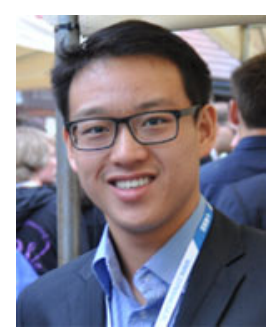

Chun Sing Lai (S'11) was born in Staffordshire, U.K. He received the B.Eng. (First Class Hons.) degree in electrical and electronic engineering from Brunel University, London, U.K., in 2013. $\mathrm{He}$ is currently working toward the D.Phil. degree in engineering science at the University of Oxford, Oxford, U.K. He is a visiting Ph.D. student at The Hong Kong Polytechnic University, Hong Kong.

His current interests include data analytics and energy economics for renewable energy and

storage systems

Mr. Lai received the IEEE SMC 2014 Student Travel Grant. He is the Chair of the IEEE Student Branch and the IEEE Power and Energy Society Student Branch Chapter at the University of Oxford. He reviews papers regularly for journals, such as the IEEE TRANSACTIONS ON INDUSTRIAL INFORMATICS and the IEEE TRANSACTIONS ON SYSTEMS, MAN AND CYBERNETICS: SYSTEMS.

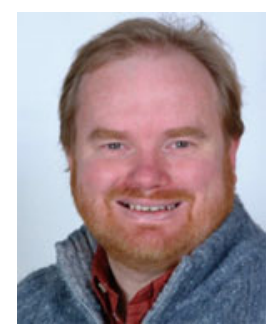

Malcolm D. McCulloch (S'88-M'89) was born in South Africa. He received the B.Sc. (Eng.) and $\mathrm{Ph} . \mathrm{D}$. degrees in electrical engineering from the University of Witwatersrand, Johannesburg, South Africa, in 1986 and 1990, respectively.

In 1993, he joined the University of Oxford, Oxford, U.K., where he started up the Electrical Power Group and is currently an Associate Professor. His work addresses transforming existing power networks, designing new power networks for the developing world, developing new technology for electric vehicles, and developing approaches to integrated mobility. He has more than 100 journal and refereed conference papers, 15 patents, and four spinout companies. 